LA-6189-MS

Informal Report

$$
\mid
$$

Uc-21

Reporting Date: December 1975

Issued: April 1976

\title{
Some Effects of Laser Irradiation on Aluminum
}

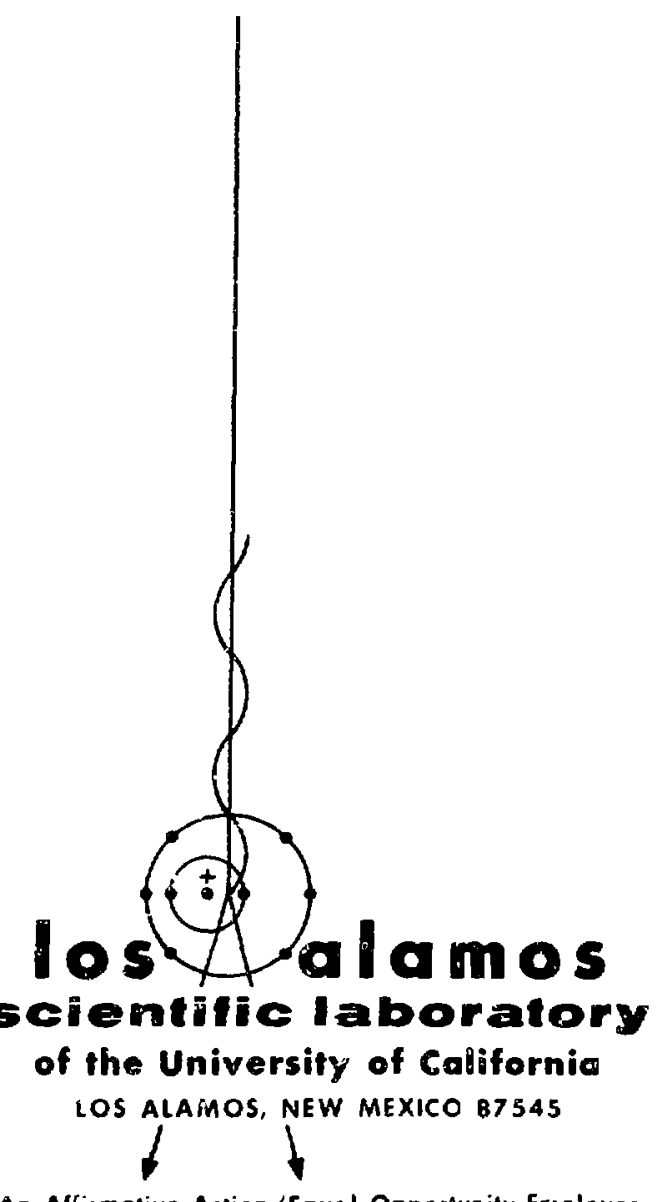

by

c. Gordon Hoifman

An Alfirmative Action/Equal Opportunity Employer 
Printed in the United States of Amsrica. Available from Nationd Technical Information Service

US Department of Commerce

5285 Port Royal Road

5285 Port Royal Road
Springfield, VA 22151

Price: Printed Copy $\$ 4.00$ Microfiche $\$ 2.25$

This repart was prepared as an ecrount of work sponsored

bs the linited Sitales Government. Neither the ínited States

nor the L'nited Stater Finergy Research and Development Ad

ministration, nor any of their employees, nor eny of their con-

warrantv, express ar imofied, or assumen any lesed liehility or

reaponaibility for the aceuracv, completeneas, or unefulnens of anv information. apparatur. product, of procesa diselosed, or repreacn 
SOME EFFECTS OF LASER IRRADIATION ON ALUMINUM

by

C. Gordon Hoffman

\begin{abstract}
Ten samples of aiuminum were irradiated by a $1.06-\mu \mathrm{m}$ mode-locked laser (25 ps) to various energy levels. The excavations were examined by optical and scanning electron microscopy. Rough computations of the mass of metal removed indicated a relationship of energy of the laser snot to the mass removed as about $9 \mathrm{~J} / \mathrm{mole}$. In some cases there is good evidence to indicate compression of the metai, but no values for this compression could be obtained.
\end{abstract}

\title{
Introduction
}

Ten aluminum (AA1700) discs of various thicknesses were irradiated with a mode-1ocked laser (25 ps) with a wavelength of $1.06 \mu \mathrm{m}$. Six of the samples were as rolled and four were annealed at $685 \mathrm{~K}\left(775^{\circ} \mathrm{F}\right)$. However, since the mechanisms operating within the metal do not seem to be sensitive to cold work, at least within the precision of the experiment, all samples are grouped together.

The energy of the laser pulses varied from $3.7 \mathrm{~J}$ to $15 \mathrm{~J}$ and in Table I the samples are grouped according to the energy in the pulse. 
TABLI. I

CRATER DIMENSIONS VERSUS ENERGY IN SHOT

\begin{tabular}{|c|c|c|}
\hline $\begin{array}{l}\text { Pulse } \\
\text { Energy } \\
\text { (J) } \\
\end{array}$ & $\begin{array}{l}\text { Approximate } \\
\text { Diameter of } \\
\text { Crater } \\
\text { (mm) }\end{array}$ & $\begin{array}{c}\text { Approximate } \\
\text { Depth of Crater } \\
\text { (mm) }\end{array}$ \\
\hline 3.7 & 0.19 & 0.11 \\
\hline 4.0 (annealed) & 0.20 & 0.11 \\
\hline 10.0 & 0.22 & 0.12 \\
\hline 10.0 & 0.26 & 0.13 \\
\hline 10.0 & 0.26 & 0.16 \\
\hline 10.0 (annealed) & 0.28 & 0.12 \\
\hline 13.0 (annealed) & 0.30 & 0.77 \\
\hline 13.8 & 0.30 & 0.18 \\
\hline 14.0 & 0.30 & 0.18 \\
\hline 15.0 (annea $7 e d)$ & 0.31 & 0.20 \\
\hline
\end{tabular}

\subsection{Joules}

Figure 1 is an SEM (Scanning electron microscope) micrograph of the crater made by the 3.7-J "shot" and Fig. 2 is an optical photomicrograph of a cross section of the same crater. Figure 3 is a sterec pair (SEM) of the crater showing "melt" which remained in the crater. A "solid wave" of molten debris from the crater extends to a distance of about 170 to 180 um from the crater after which the wave had been broken up into a spray. Also, there is a considerable amount of melt in evidence within the crater itself. (This will be discussed a little later in connection with Fig. 24 which shows the cross section of the prior melt a little better.) Figure 3 is a stereo pair of the crater. 


\section{Joules}

Figures 4 and 5 are SEM micrographs of the crater made by a 4-J shot.

Figure 6 shows a spalled area on the back surface of the aluminum sheet opposite the crater. The equiaxed grains of the aluminum show up very well.

Figure 7 is an optical metallographic view of the cross section through the crater and the spalled area in back of it. 10 Joules

There are four 10-J shots as shown $i_{11}$ Figs. 8, 9, 10, and 11 ; Figs. 12, 13, and 14; Figs. 15, 16, and 17; and Figs. 18, 19; 20, and 21.

These show the SEM micrographs of the craters and then the cross sections through the craters. A great deal of molten aluminum has settled back into the crater prior to solidification.

\section{Joules}

Figures 22 and 23 are SEM micrographs of the 13-J shot and show a considerable amount of solidified melt within the crater.

Figure 24 is a cross section through the crater, in the bottom of which is shown a layer of snall columnar grains of alumirum which are the result of solidification from a melt.

\section{Joules}

There were two shots of essentially the same energy, 13.8 and $14 \mathrm{~J}$. Figures 25 and 26 show the SEM pictures of the 13.8-J crater and Fig. 27 is a stereo pair of it. Notice the large "lump" of melt material. Figure 28 shows the rear surface of the sheet behind the crater and Fig. 29 shows a cross section of the crater and the concomitant spall. The cross section of the lump mentioned above reveals by the columnar grain formation that it 
was indeed molten at one time and solidified by losing heat to the solid sheet of aluminum. It will be noted also that the elongated (cold-worked) grains of the aluminum have been bent around the crater in a manner which indicates very strongly that there was strong compression of the aluminum, since there is no corresponding bend at the rear surface, in fact there was a spal1.

Figures 30 and 31 are SEMs of the 14-J crater and Fig. 32 shows the rear spalled surface. All show a small area of complete penetration. Figure 33 shows a cross section of the crater, multiple spall, and the penetration "channe1." Figure 34 shows an enlarged view of a small area of columnar grains in the bottom of the crater. It is noteworthy how cleanly the penetrating channei has been "cut" through the sheet, i.e., there is no deformation of the cold-worked grains of the aluminum right up to the very edge of the channei as was seen in alj of the crater, indicating a completely different mechanism operating.

\section{Joules}

Figures 35 and 36 are SEM micrographs of the "front" and the "rear" of the 15-J shot. There is the usual ejection of vapor and molten material from the crater and spalling from the ream surface. But in addition there is a small hole completely through the aluminum sheet. Figures 37 and 38 show cross section through the hole at two different planes. Note the intergranular tensile rupturing and the spalling in Fig. 37 and the complete penetration of the sheet in Fig. 38 . 
It will be noted from Table II that the depth of each crater is approximately half of the diameter and from the cross-section photomicrographs that the crater is very roughly hemispherical in shape. If we then assume a density of aluminum as $2.7 \mathrm{~g} / \mathrm{cm}^{3}$ the mass of metal removed from each crater is as given in Table II.

These results are, of course, very rough approximations but do show a pattern and suggest that there is a direct relationship between metal removed and laser energy, i.e., approximately $3 \mu \mathrm{g} / \mathrm{J}$ or $9 \times 10^{6} \mathrm{~J} / \mathrm{mole}$.

TABLE II

MASS REMOVAL PER SHOT

\begin{tabular}{|c|c|c|}
\hline $\begin{array}{l}\text { Pulse } \\
\text { Eneray } \\
\text { (J) }\end{array}$ & $\begin{array}{l}\mu g \text { of } A 1 \\
\text { Removed }\end{array}$ & $\underline{\mu g} / \mathrm{J}$ \\
\hline 3.7 & 11.2 & 3.0 \\
\hline 4.0 & 12.4 & 3.1 \\
\hline 10.0 & 15.3 & $1.5^{\mathrm{a}}$ \\
\hline 10.0 & 24.8 & 2.5 \\
\hline 10.0 & 30.4 & 3.0 \\
\hline 10.0 & 26.6 & 2.7 \\
\hline 13.0 & 43.0 & 3.3 \\
\hline 13.8 & 45.2 & 3.2 \\
\hline 14.0 & 45.2 & 3.1 \\
\hline 15.0 & 52.5 & 3. \\
\hline
\end{tabular}

aprelasing is suspected. 
This number can be thought of as a rough phenomenological energy although the contributions of its many components are not known. Heats of melting and vaporization are known, energy of ionization can be had, kinetic energy and shock energy might be calculated, but what portions of the mass are subjected to each ni these mechanisms is not yat known. 


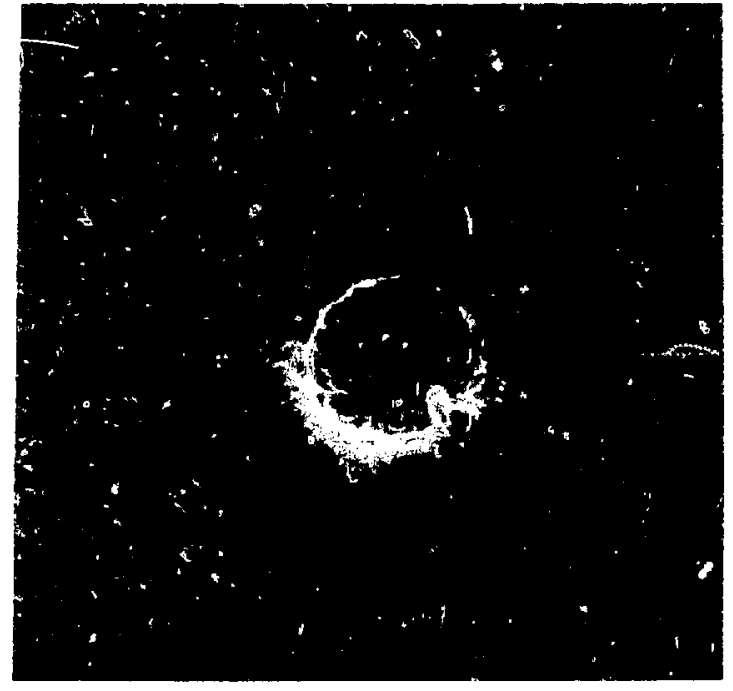

$100 x$

Fig. 1. SEM - Front surface of crater.

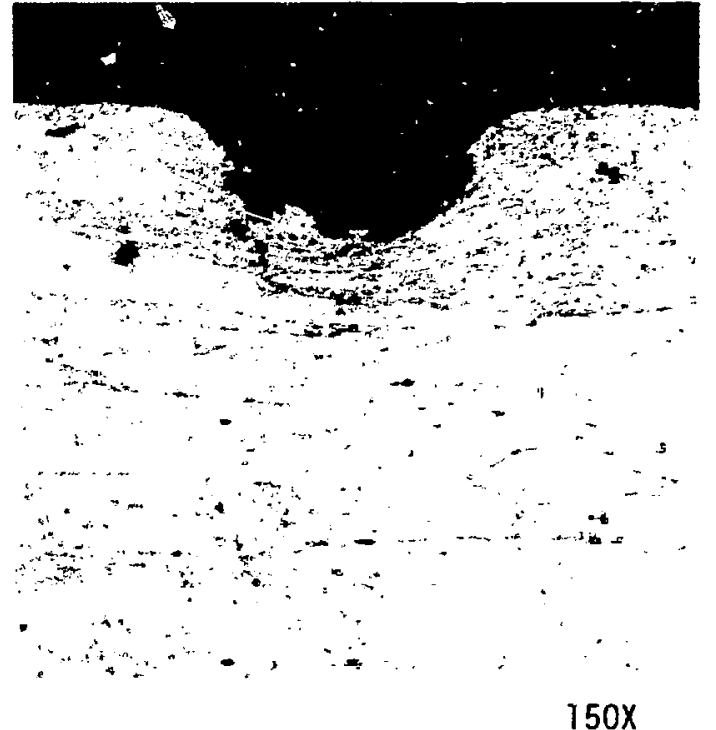

Fig. 2. Cross section of crater.

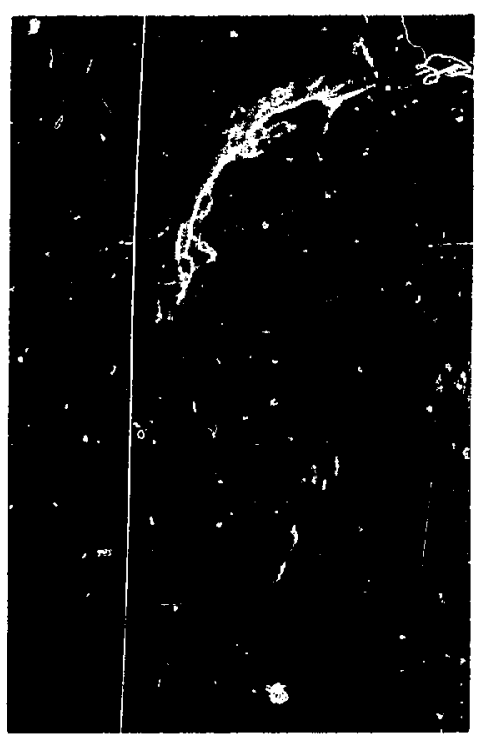

Fig. 3. Stereo pair - Front surface.

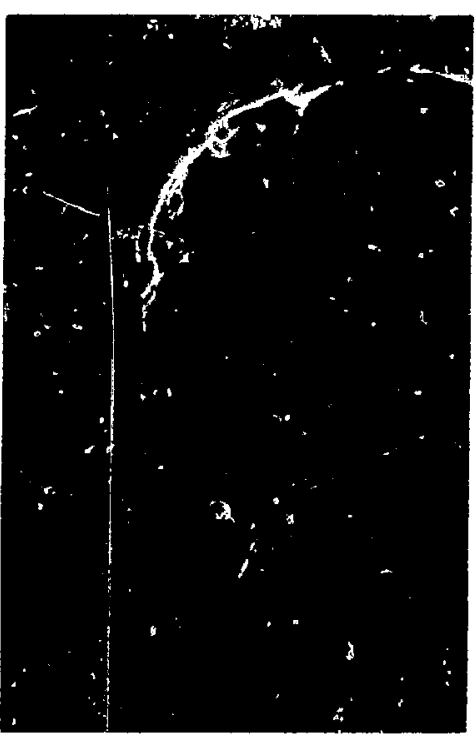

$300 x$ 


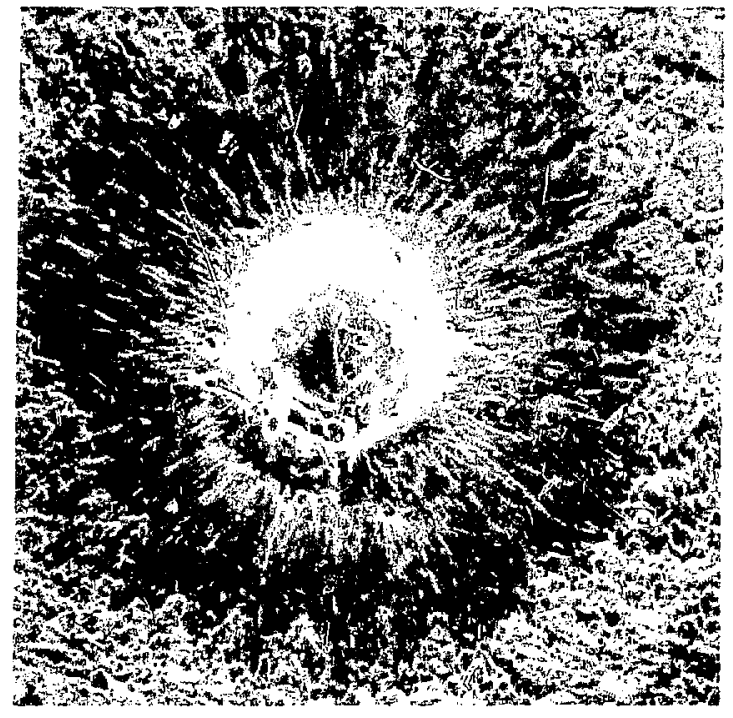

$100 x$

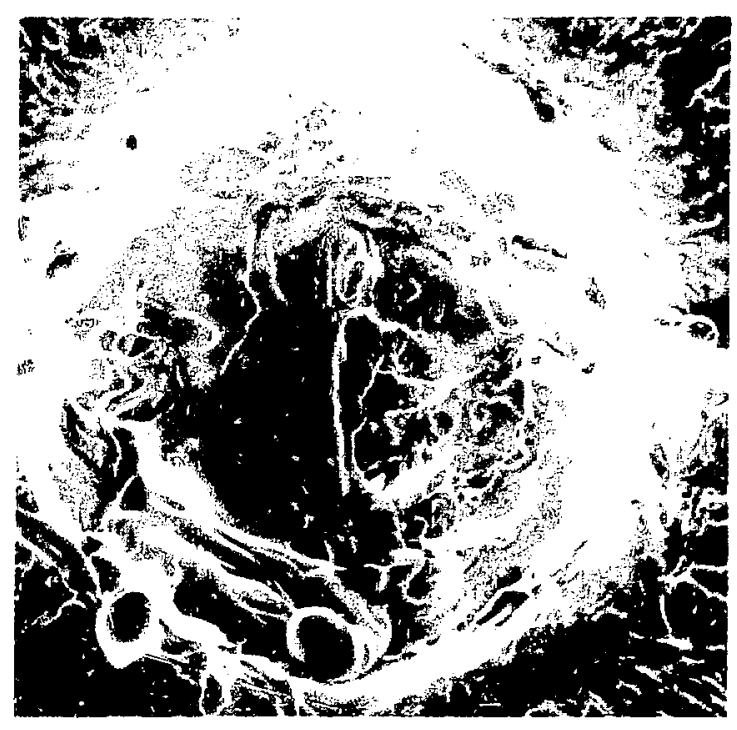

$300 x$

Fig. 5. Same - Higher power.

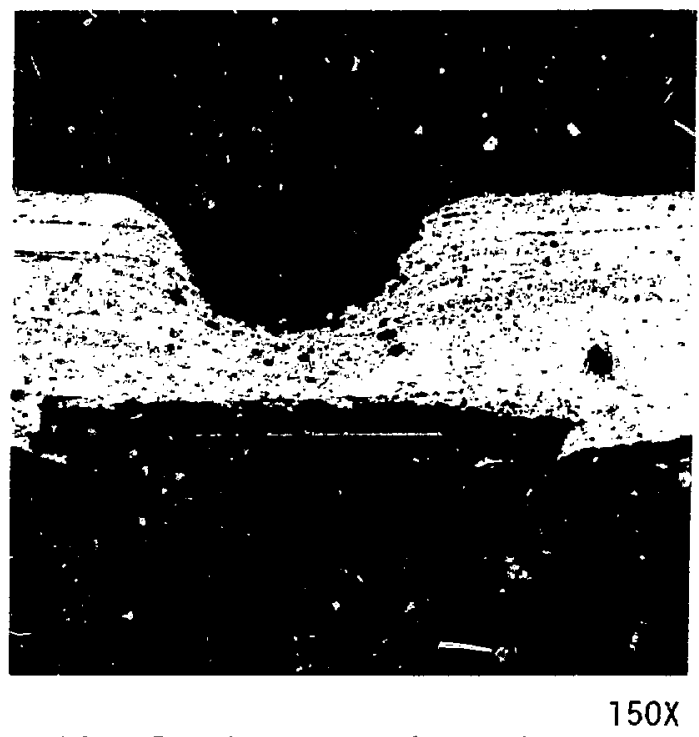

Fig. 7. Cross section - Crater and spali. 


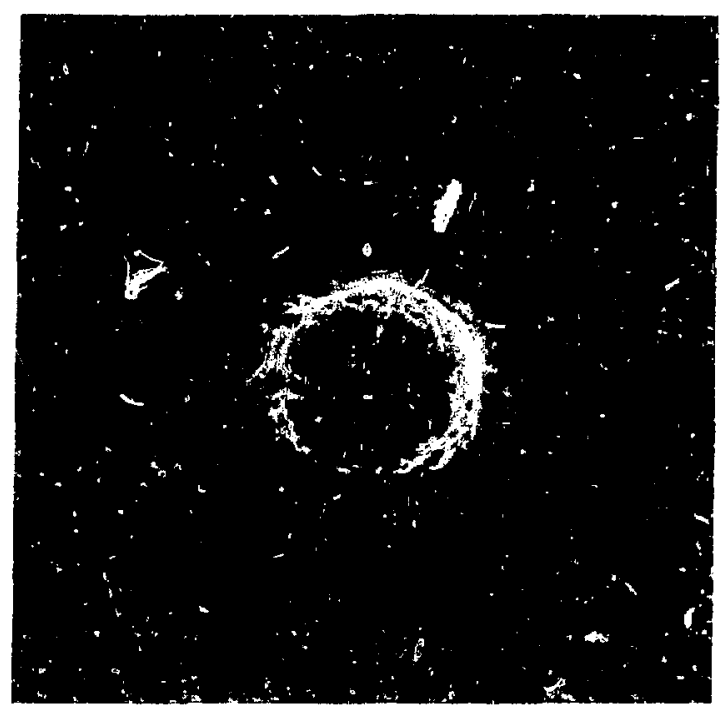

Fig. 8. SEM - Front surface.

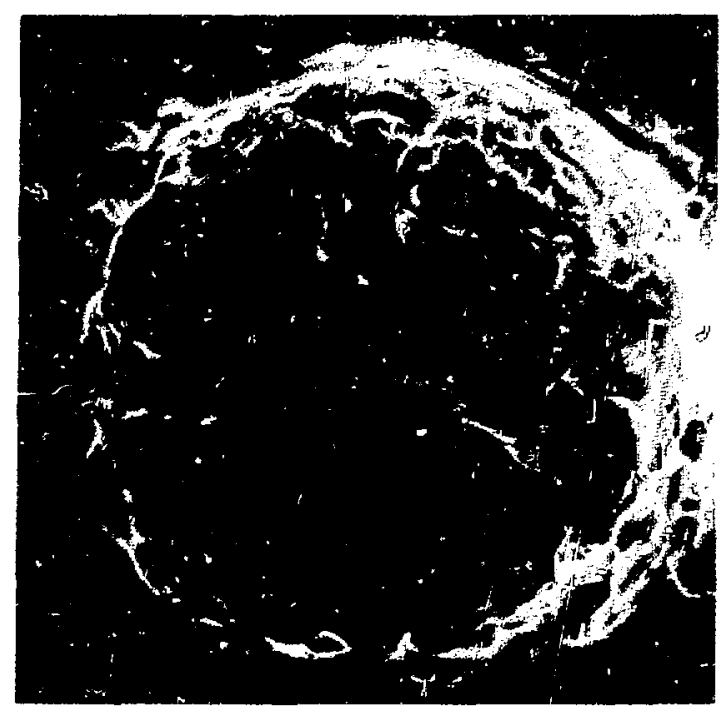

Fig. 9. Süme - Enlargeú.
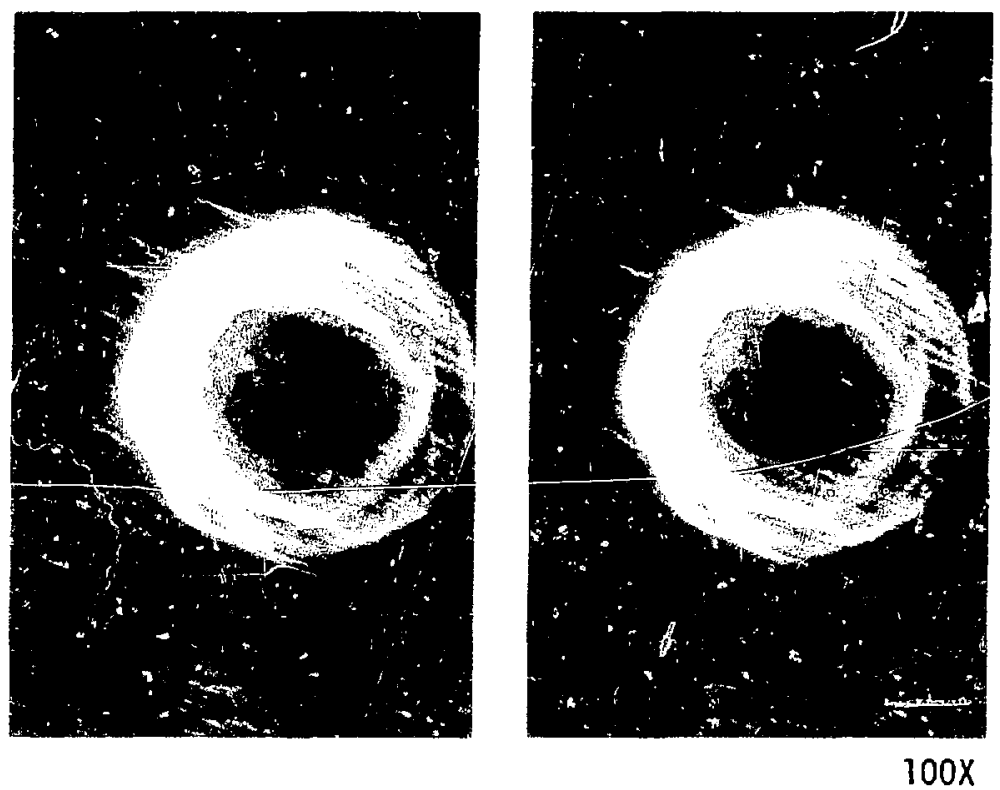

Fig. 10. Stereo pair - Rear surface showing spall. 


\section{Joules}

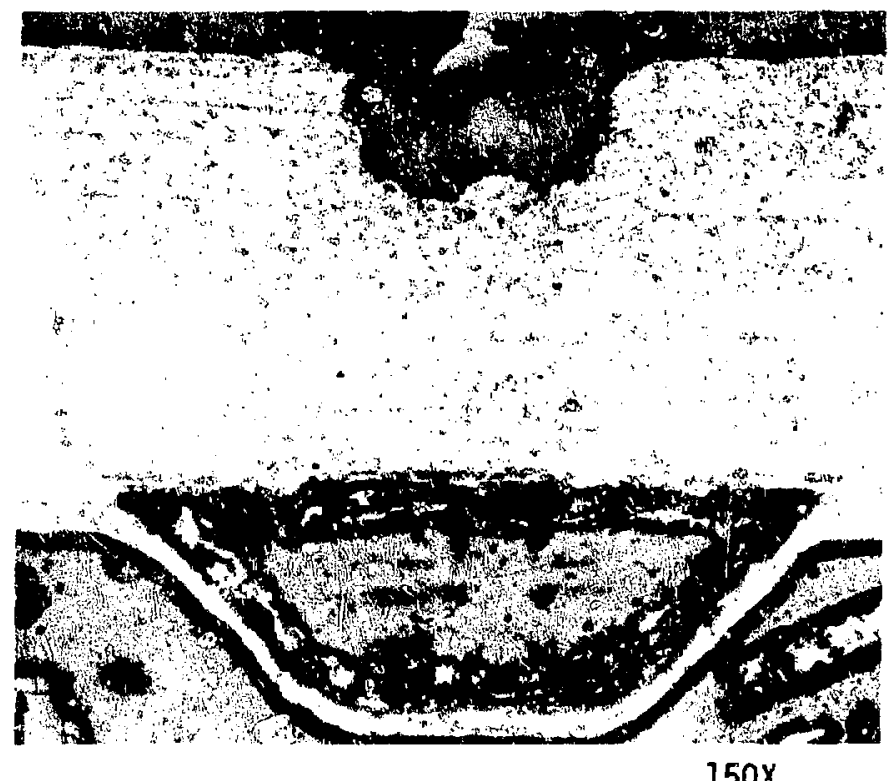

Fig. 11. Cross section - Crater and spall. 


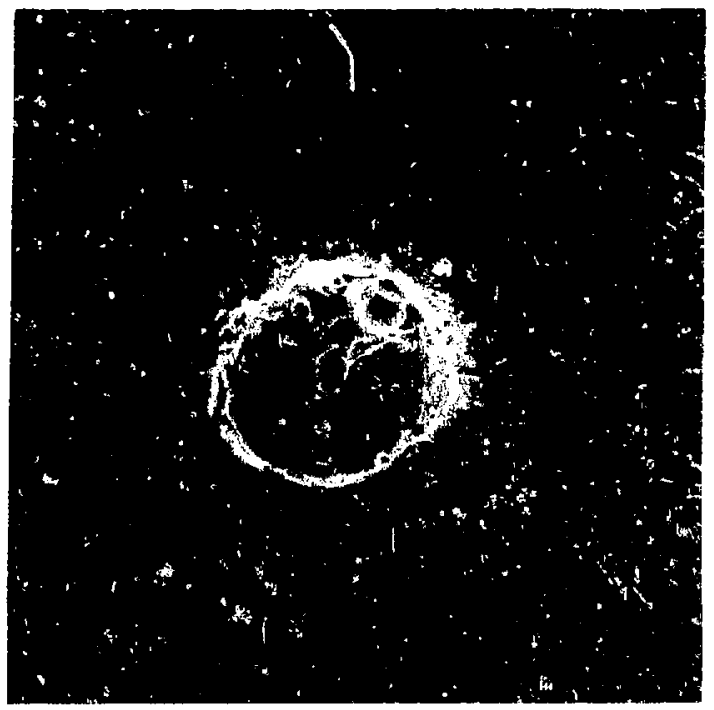

$100 x$

Fig. 12. SEM - Front surface.

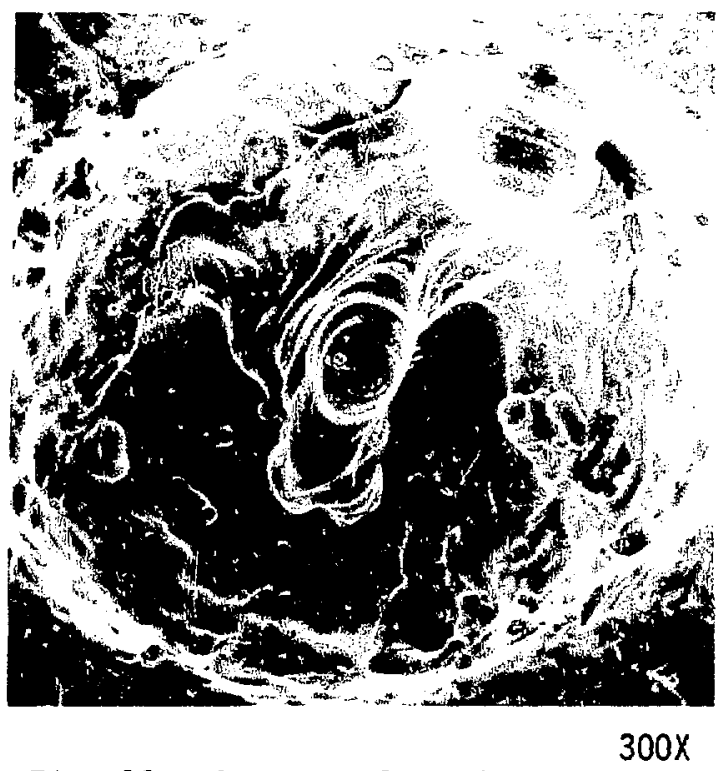

Fig. 13. Same - Enlarged.

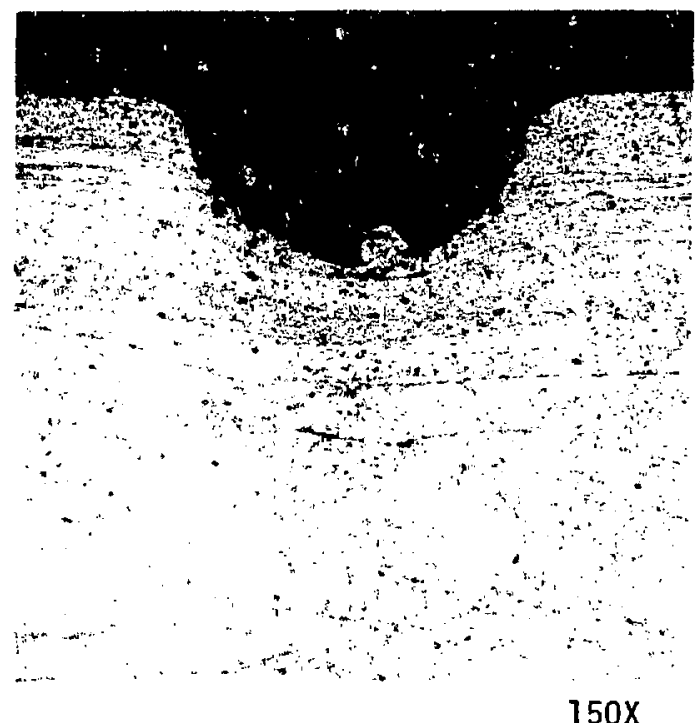

Fig. 14. Cross section - Crater. 

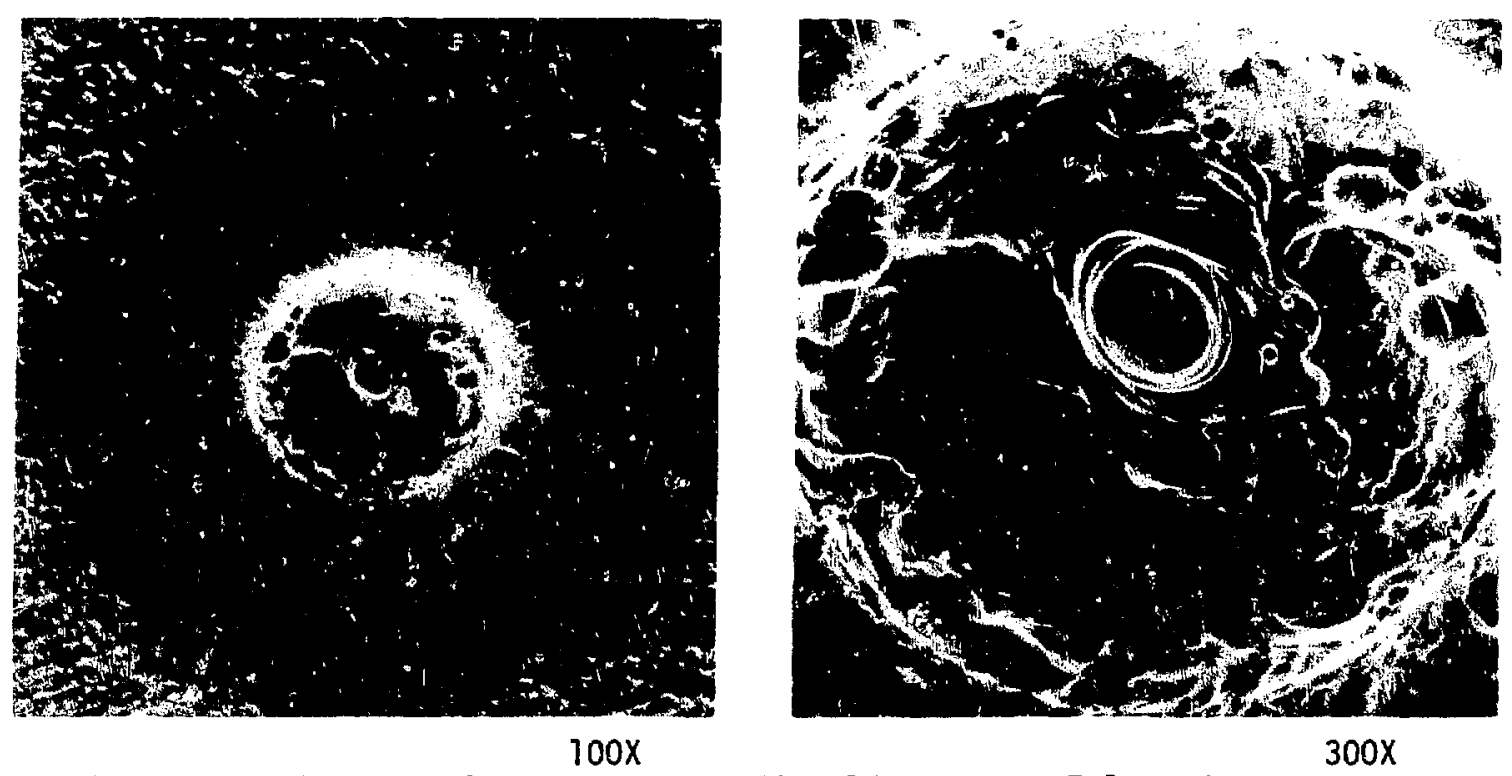

Fig. 15. SEM - Front surface.

Fig. 16. Same - Enlarged.

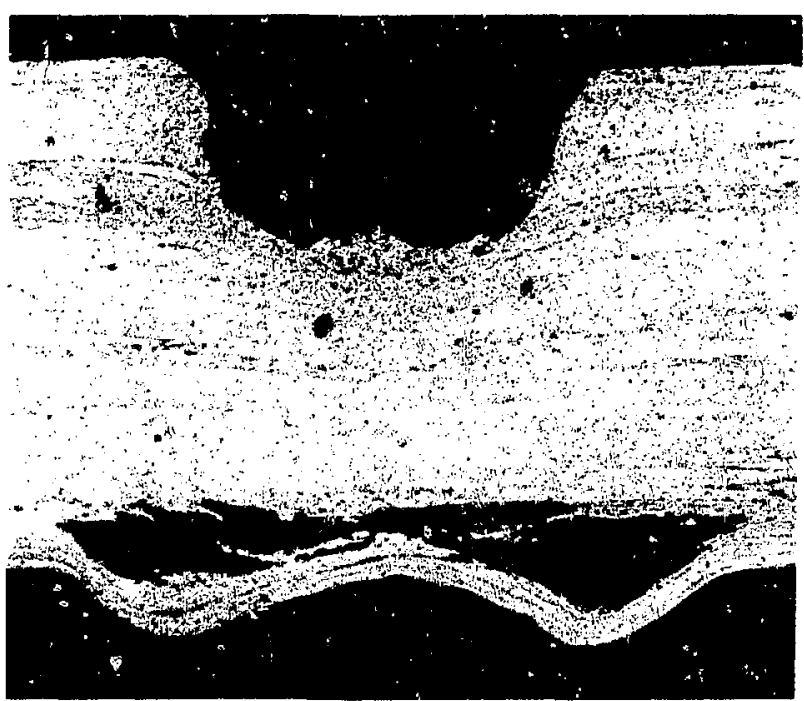

$150 x$

Fig. 17. Cross section - Crater and spall. 
10 Joules
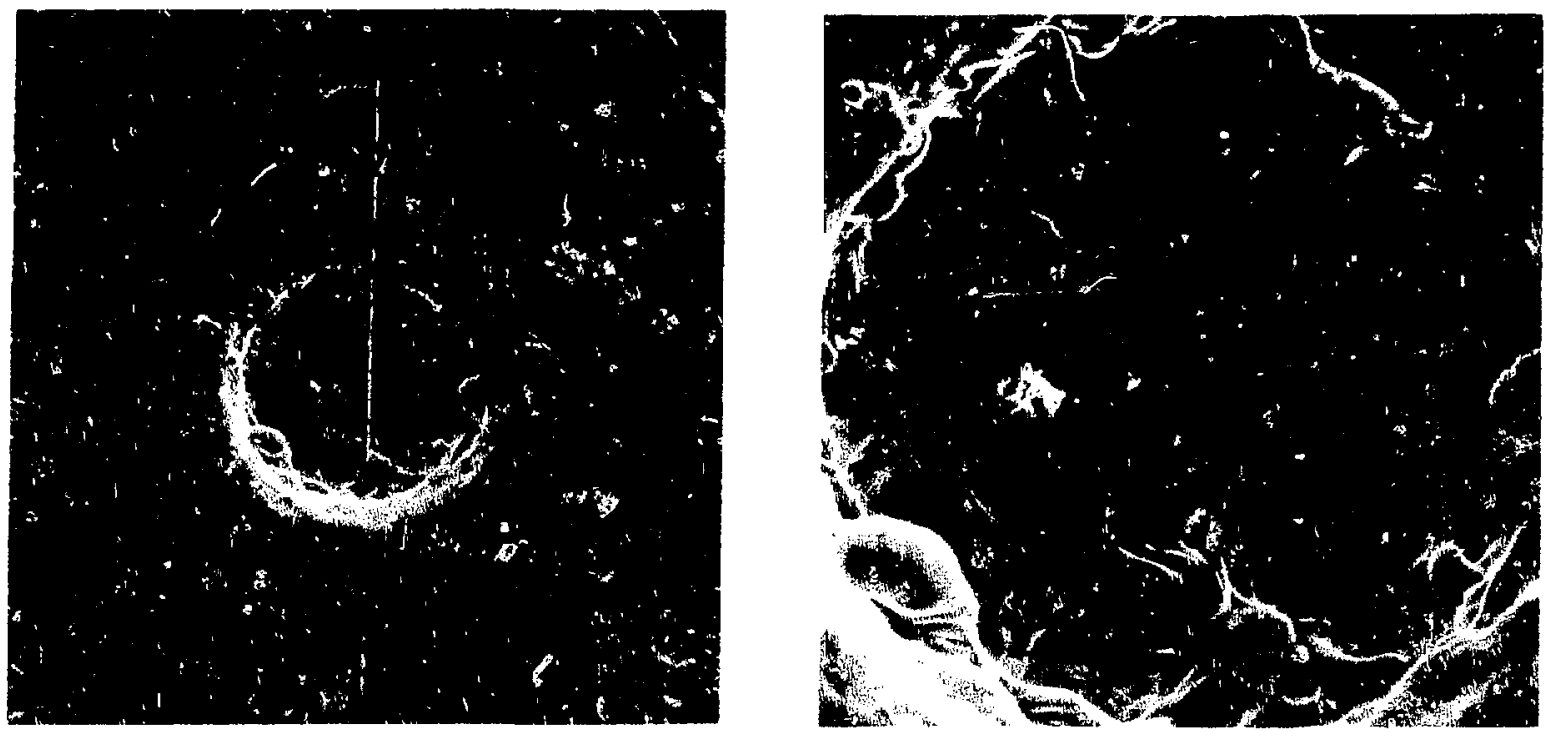

Fig. 18. SEM - Front surface.

$100 x$

Fig. 19. Same - Enlarged

$300 x$
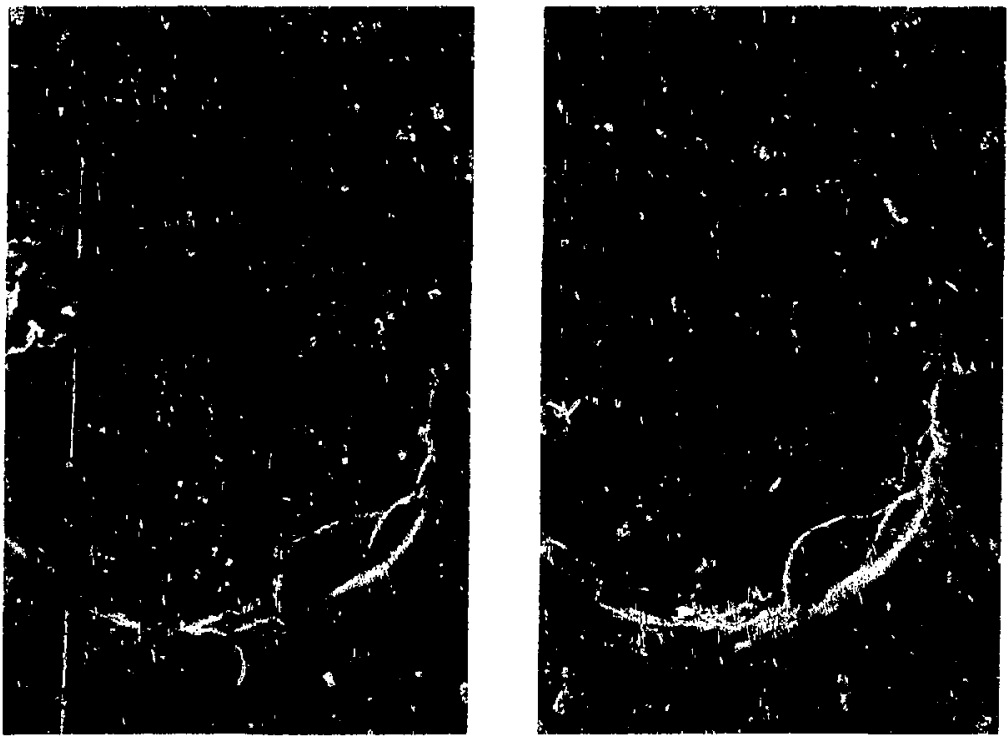

$250 x$

Fig. 20. Stereo pair - Front surface. 
10 Joules

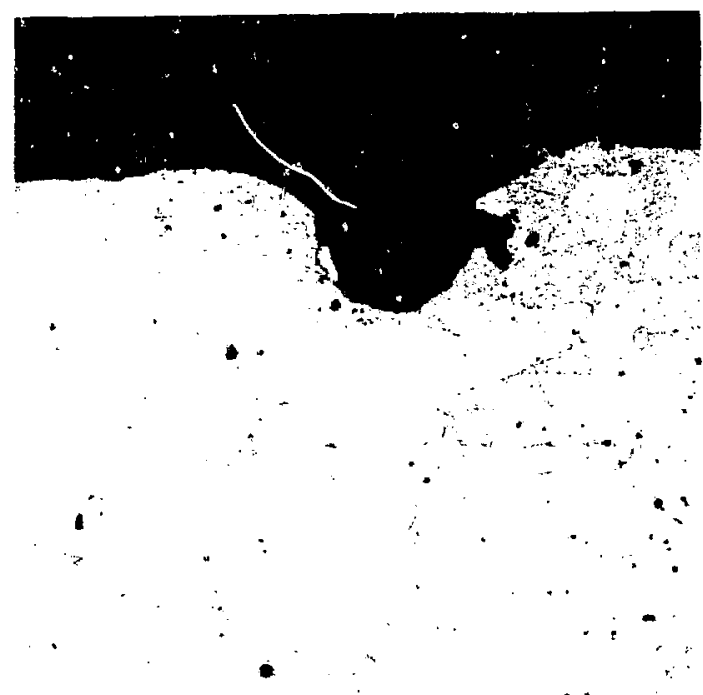

$150 x$

Fig. 21. Cross section of crater. 


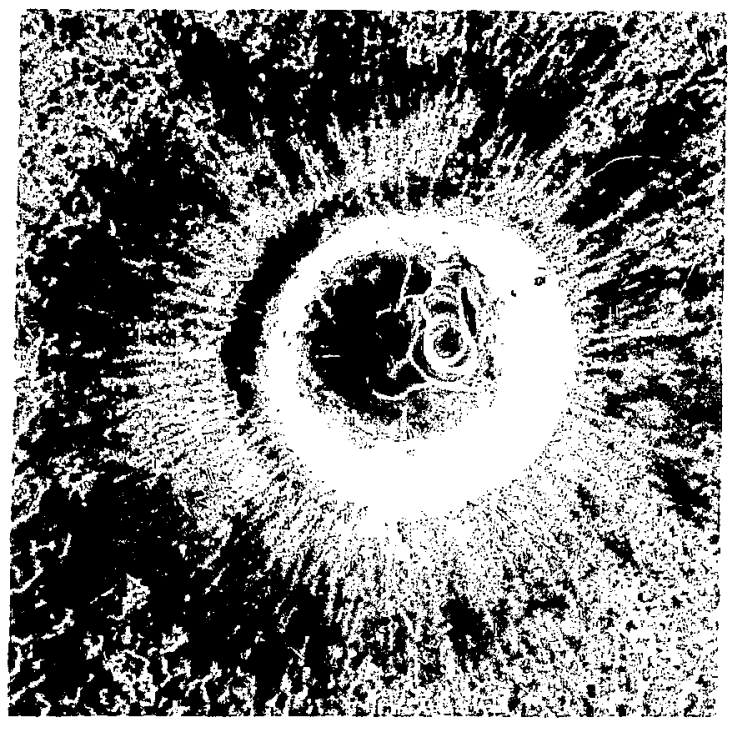

$100 x$

Fig. 22. SEM - Front surface.

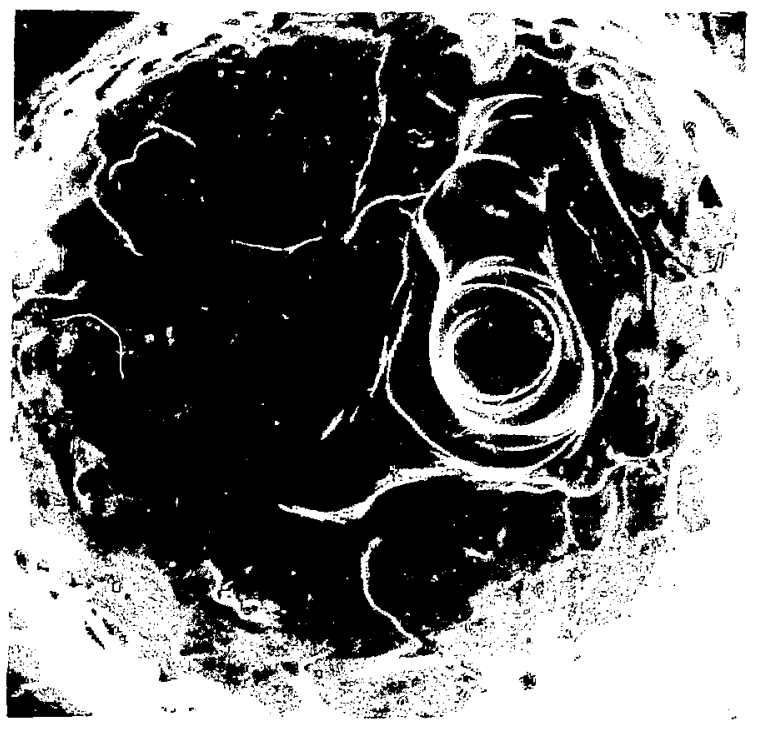

$300 x$

Fig. 23. Same - Enlarged.

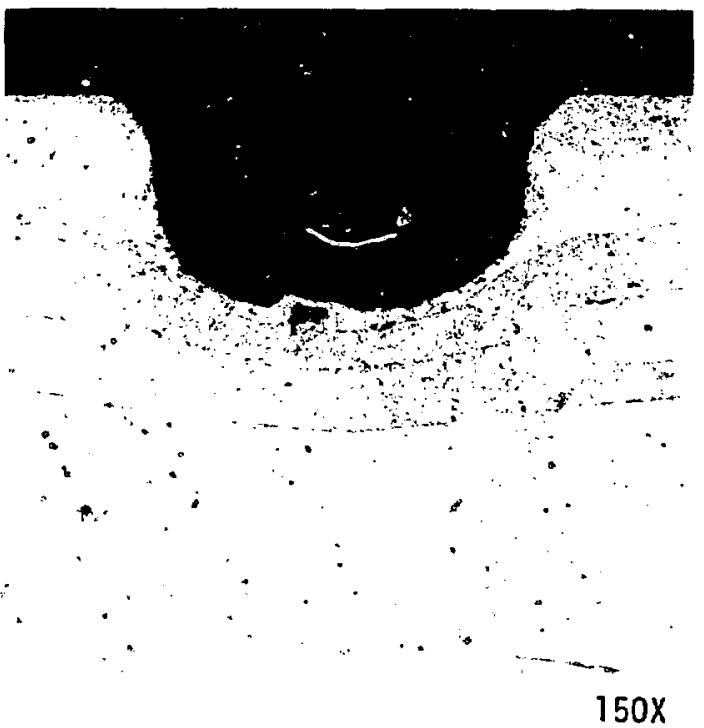

Fig. 24. Cross section - Crater with columnar grains in bottem surface indicating melt. 


\subsection{Joules}
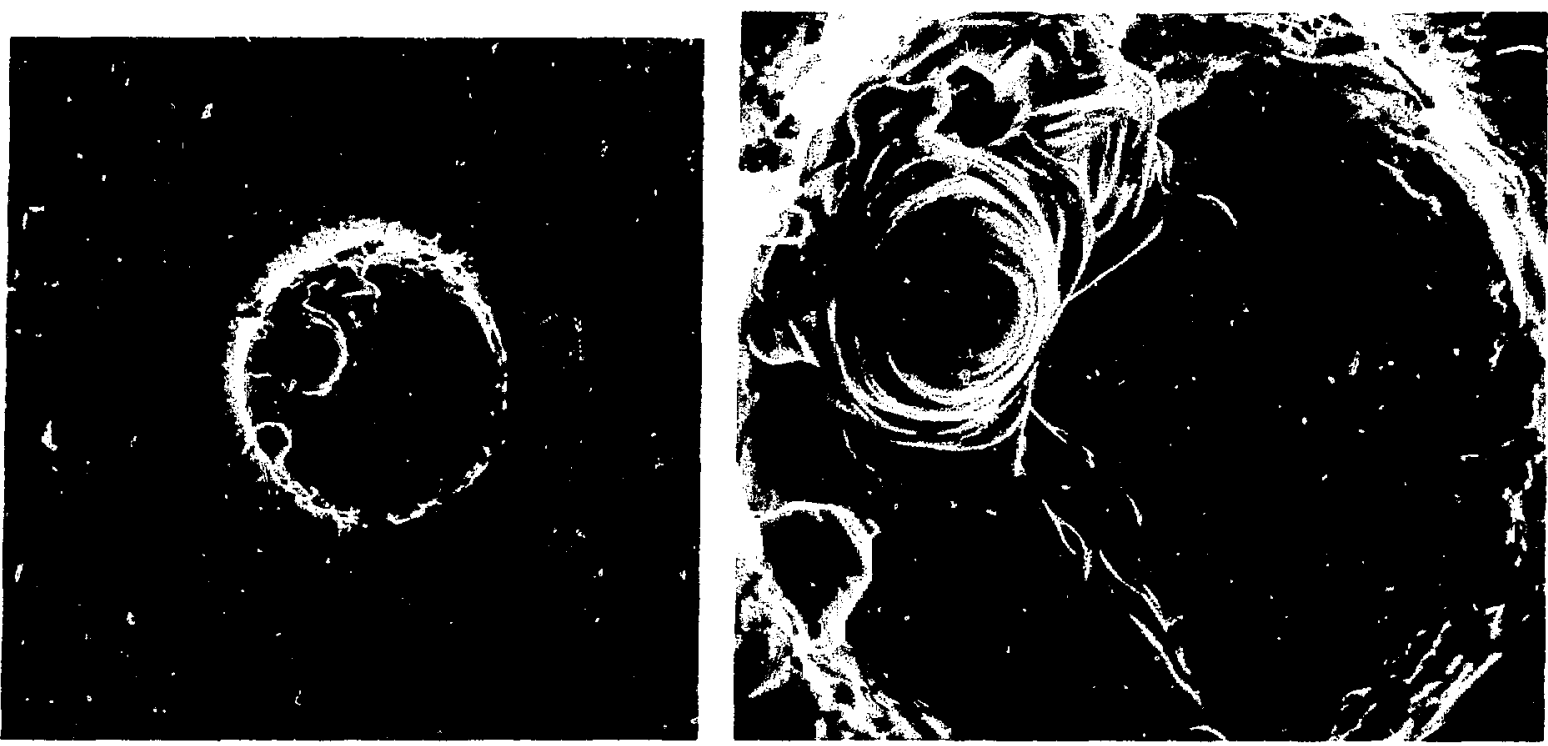

$100 x$

Fiy. 25. SEM - Crater.

Fig. 26. Sane - Enlarged.

$300 x$

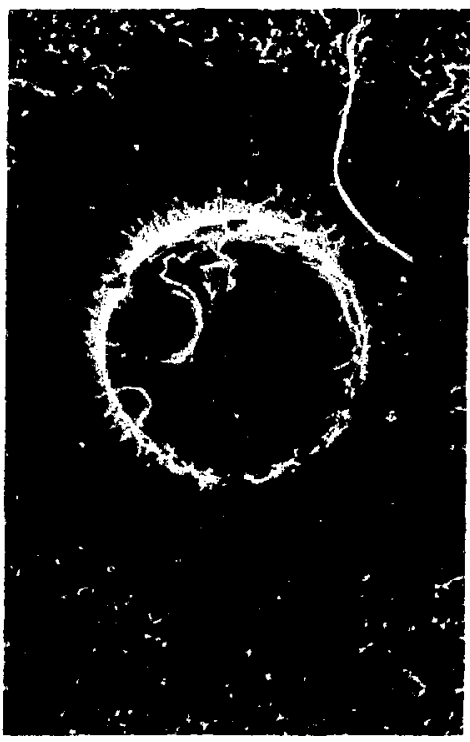

Fig. 27. Stereo pair of crater.

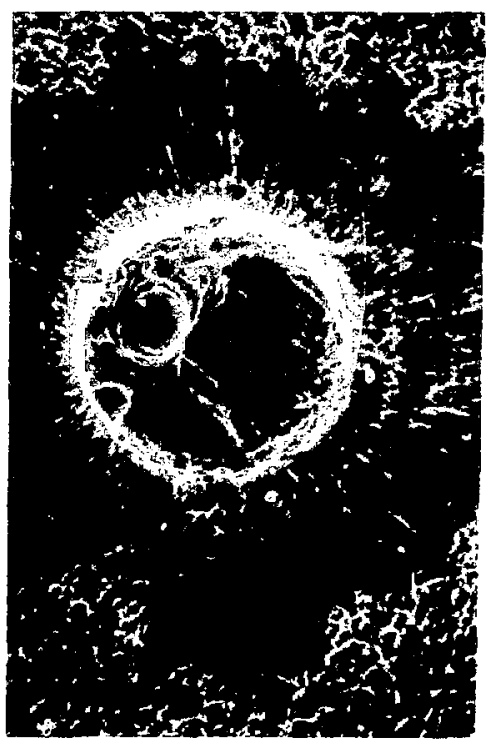

$100 x$ 


\subsection{Joules}

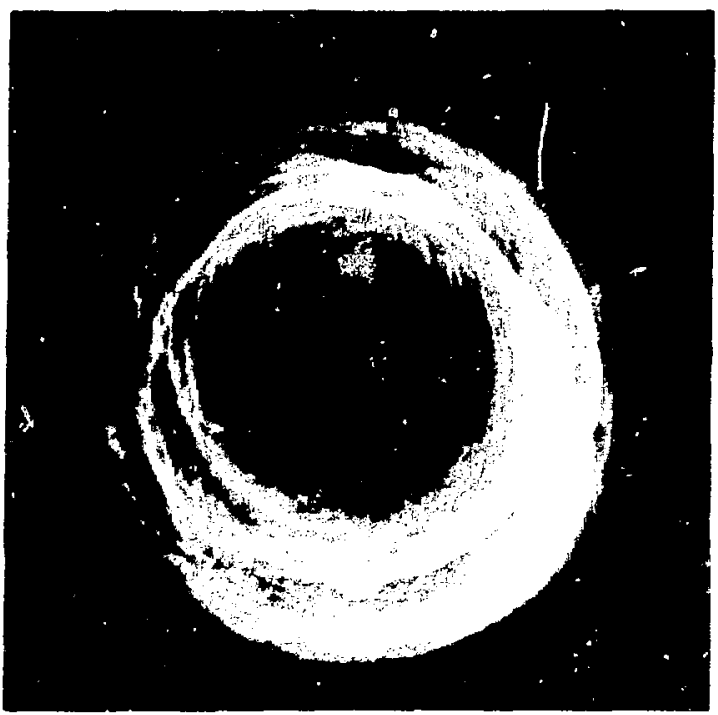

$100 x$

Fig. 28. Rear surface showing spall.

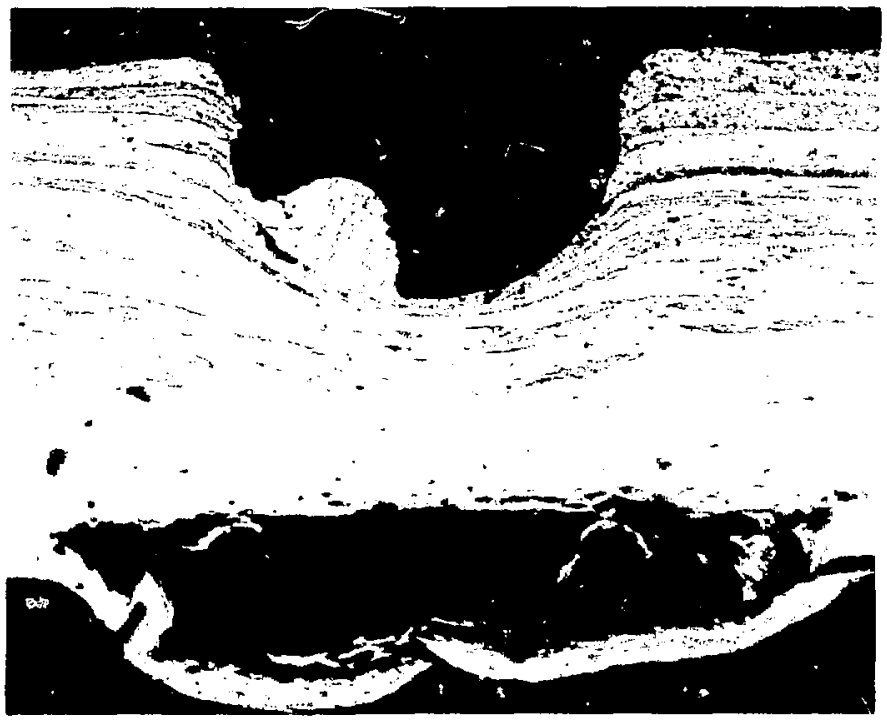

$150 x$

Fig. 29. Cross section showing crater and spall. Columnar grains in droplet indicate melt. Deformation of elongated aluminum grains indicates compression. 
14 Joules

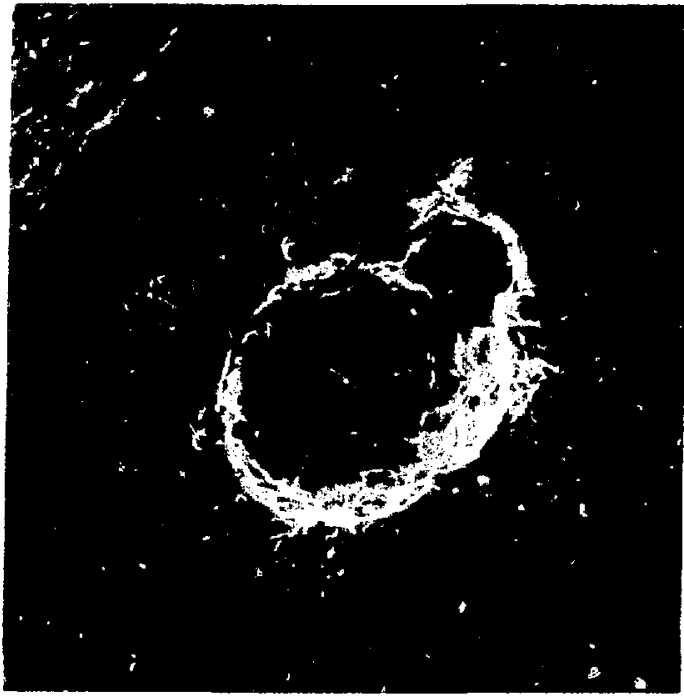

$100 x$

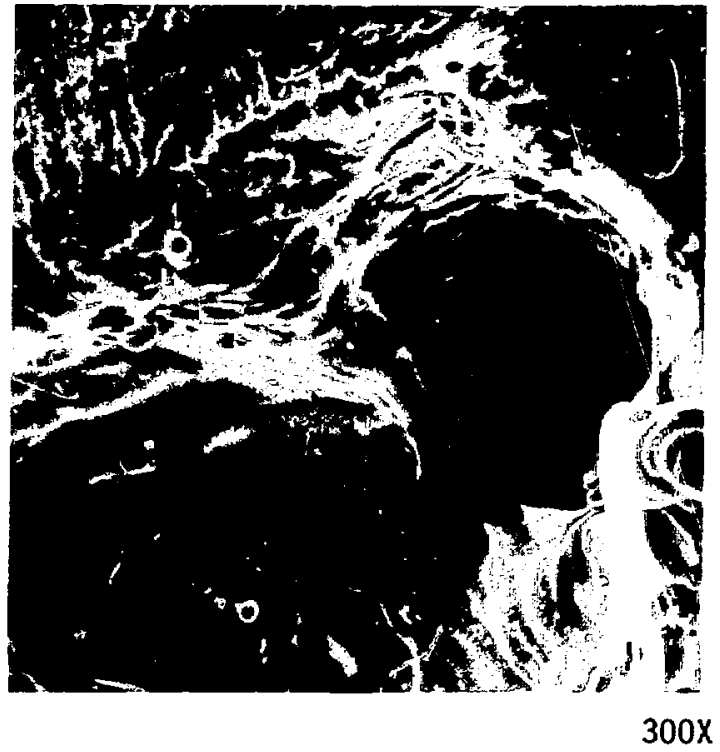

Fig. 31. Same - Enlarged.

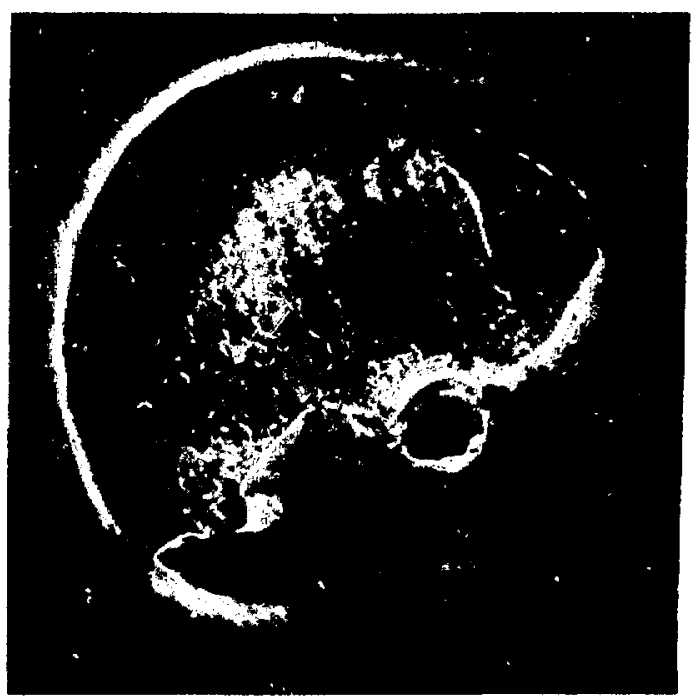

$100 x$

Fig. 32. Rear surface - Showing spall and penetrating "tunnel."

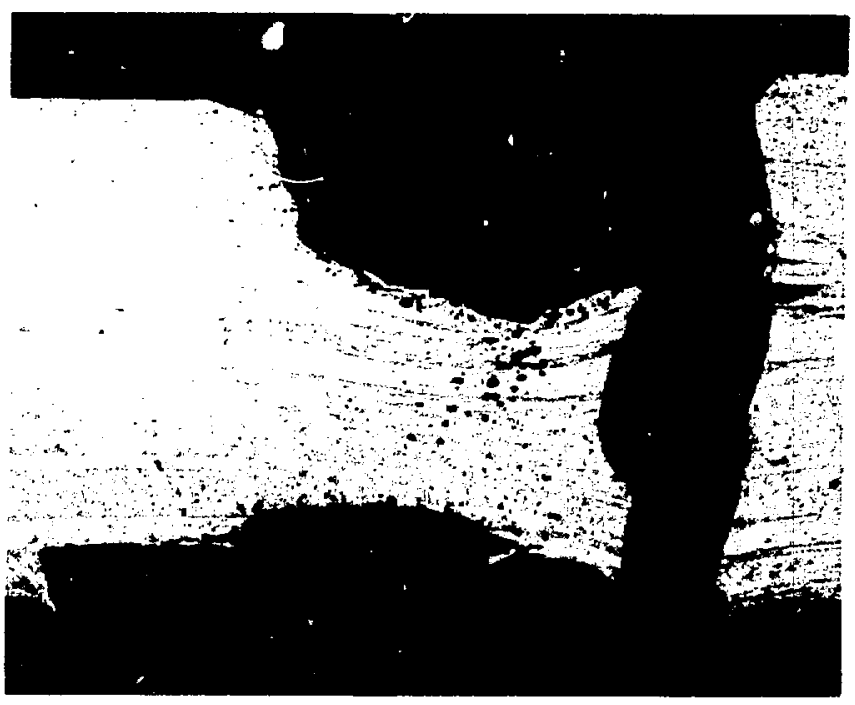

$150 x$

Fig. 33. Cross section - Showing crater spall and tunnel through the disc. 
14 Joules

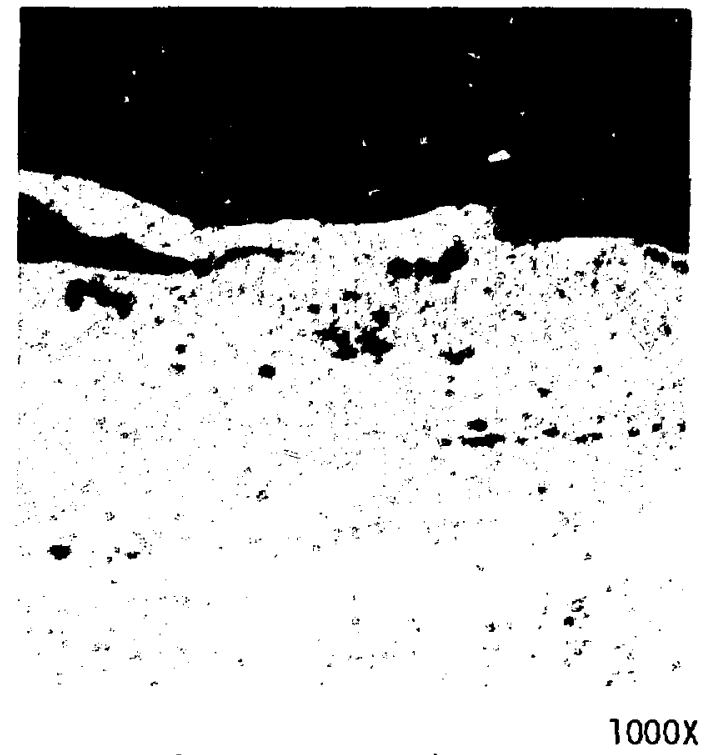

Fig. 34. Cross section through bottom of crater - Showing columnar grains. 


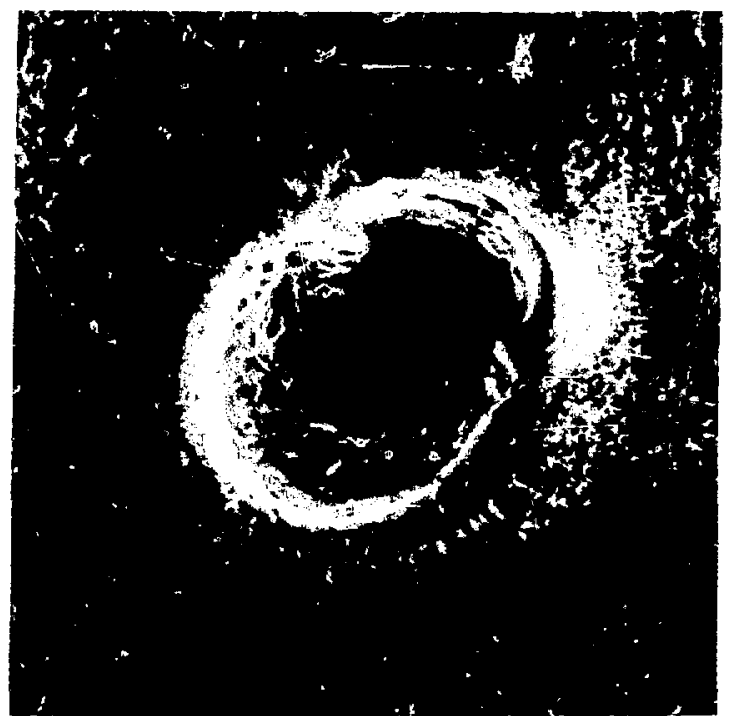

$100 x$

Fig. 35. SEM of crater and penetrating tunnel.

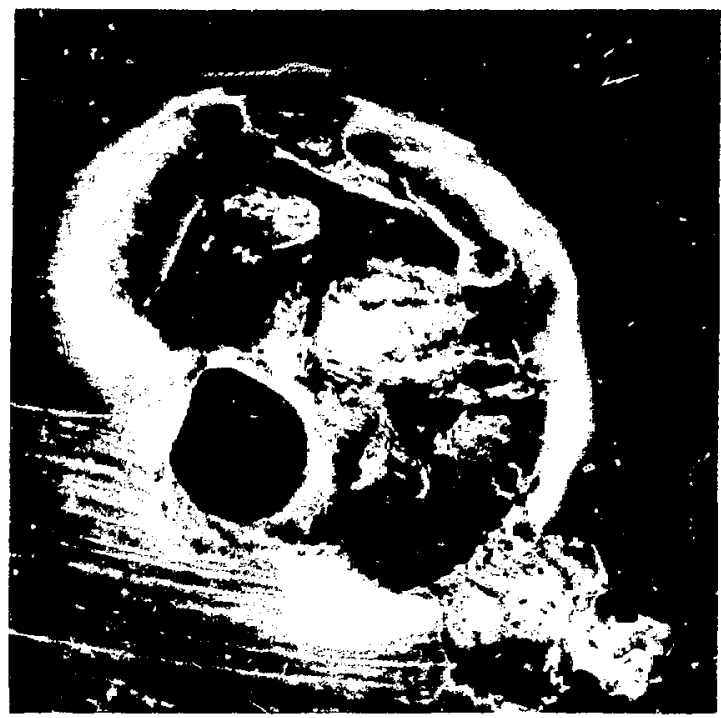

$100 x$

Fig. 36. Rear surface showing spall and tunnelling.

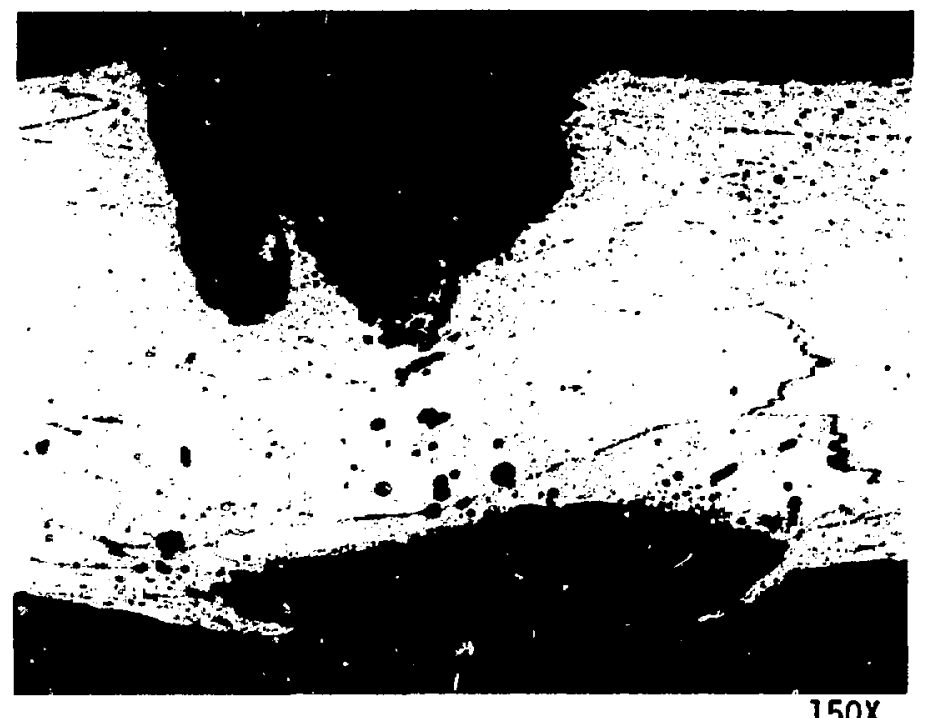

Fig. 37. Cross section about $30 \mu \mathrm{m}$ from center showing crater, spall, portion of penetrating tunnel, and tensile separation of grains. 


\section{Joules}

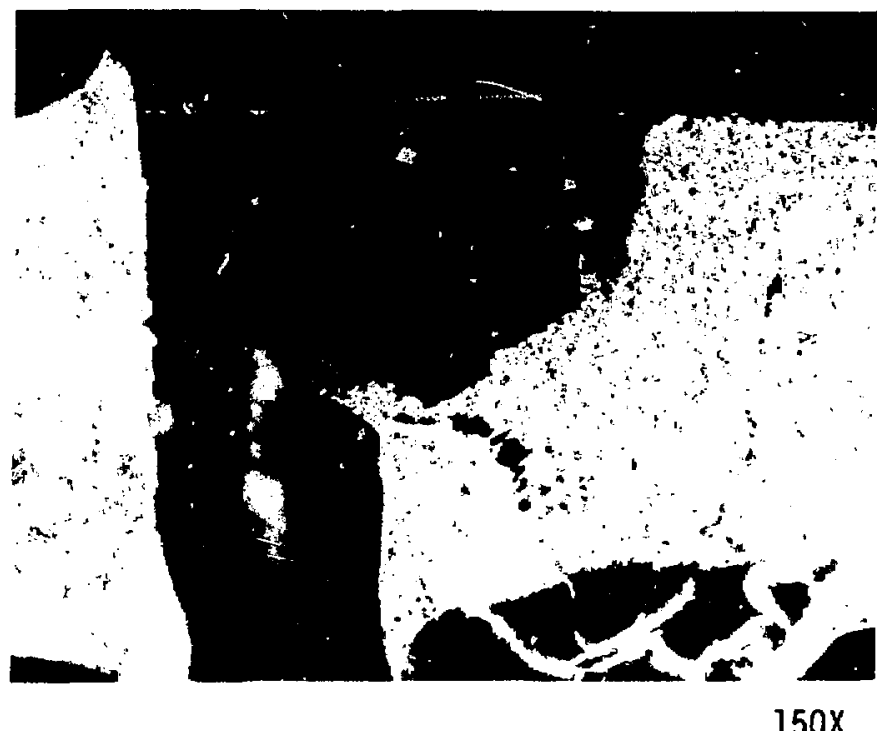

Fig. 38. Same as Fig. 37 but closer to center of crater and tunnel. 
NOTE ADDED

R. P. Godwin

The beautiful photomicrographs in this report give some quantitative information on laser-target interactions. We disregard in this discussion the "penetration channel" feature, for which we have no explanaticn.

The physics of the microcraters is strikingly similar to that of an ideal point explosion on a semi-infinite surface bounded by vacuum. ${ }^{1}$ An example is meteorite impact. Indeed Hoffman's photographs are very much Iike Apollo Lunar crater photos. In the laser-target interaction problem we have a disc of heated material rather than a point. Other than that our conditions satisfy those required for the point explosion analysis.

A comparison of Hoffman's photos with Figs. 12.17 and 12.18 of Zel'dovich and Raizer shows great similarity. Note that Fig. 12.17 indicates the origins of both the radial ejecta around the craters and the resolidified molten material in the craters. One feature is distinctly different.

Zel'dovich and Raizer predict a crater depth to diameter ratio of about unity. We find upon averaging the data of Table I that depth $\div$ diameter $=$ $0.57 \pm 0.06$. (Here and later we have discarded the first listed 10.0-J shot. On that shot the laser prelased giving rise to a long low-intensity pulse.) Note, however, that Zel'dovich et al. have assumed a point explosion. If we correct crudely for the diameter of our foral spot by a linear subtraction of $105 \mu \mathrm{m}$ from the measured diameters we find

$$
\text { depth } \div \text { (diameter-105 } \mathrm{\mu m})=1.0 \pm 0.2
$$

While 105 um was chosen to give this result, indepent estimates of the spot diameter give similar results. 
We find from Table II that the energy required to remove a given mass of aluminum is independent of the incident energy and is

$$
3.04 \pm 0.28 \mu \mathrm{g} / \mathrm{J}
$$

The actual energy impinging on the target is 0.84 of the values quoted in Tables I and II (due to reflection losses on the target chamber window, etc.), so that actually

$$
3.6 \pm 0.3 \mu \mathrm{g} / 3
$$

which corresponds to about

$$
8 \times 10^{6} \mathrm{~J} / \mathrm{mole} \text {, }
$$

is the proper vaiue.

Zel'dovich suggests that the energy required for shock vaporization is about $10 \Delta E_{v}$, where $\Delta E_{v}$ is the heat of vaporization. Since $\Delta E_{v}$ for aluminum is $2.93 \times 10^{5} \mathrm{~J} / \mathrm{mole}^{2}$ we expect to need about

$$
3 \times 10^{6} \mathrm{~J} / \mathrm{mole}
$$

for shock vaporization. If Zel'dovich's estimate is reasonable we are converting about $3 / 8$ or $40 \%$ of the incident laser energy into shock heatirg of the target. Similar results have been obtained by measuring shocks in a helium background gas.

We can obtain related information from the work of Larson. ${ }^{3}$ He has performed one-dimensional calculations of the spailation of alumirum for a variety of laser and target conditions. While Hoffman's photos could be compared with code calculations of spall, we will compare only vith Larson's mass removal calculations. Since impulse $\simeq \sqrt{2 M E}$, (easily shown from conservation of momentuin and energy) where $M$ is the mass removed and $\tilde{F}$ the 
energy deposited, material pressures and spallation are intimately related to the mass removal. Our laser wavelength, pulse length, and energy/area are $1.06 \mathrm{um}, 25 \mathrm{Fs}$, and $\sim 10^{5} \mathrm{~J} / \mathrm{cm}^{2}$, respectively; conditions which Larson has not calculated. One can guess from his Figs. 17 and 21 , however, that he would find

$$
\sim 6 \mathrm{\mu g} / \mathrm{J} \text {. }
$$

We found $3.6 \mu \mathrm{g} / \mathrm{J}$, i.e., $60 \%$ of this value.

We have measured somewhat lower mass removal in our $1.06 \mu \mathrm{m}$-experiments than is calculated from simple one- or three-dimensional models. Reduced mass removal leads to lower pressures at the target surface.

Such experiments may be useful for equation-of-state studies on a small scale. We should perform similar aralyses upon targets exposed to $10.6-\mu \mathrm{m}$ radiation to investigate their assumed greatly reduced mass removal.

\section{References}

1. Y. B. Zel'dovich and Y.P. Raizer, Physics of Shock Waves and High Temperature Prienomena Vol. II (Academic, New York, 1967), p. 839-846.

2. American Institute of Physics Handbook (McGiraw-Hi11, New York, 1972), p. 4-223.

3. A. R. Larson, "Calculations of Laser-Induced Spall in Aluminum Targets," Los Alamos Scientific Laboratory report LA-5619-MS (May 1974). 